\title{
Displacement mapping of point clouds: application of retaining structures composed of sheet piles
}

\author{
Yang Zhao ${ }^{1} \cdot$ Hyungjoon $\mathrm{Seo}^{2}$ (D) Cheng Chen ${ }^{1}$
}

Received: 4 March 2021 / Revised: 5 May 2021 / Accepted: 9 May 2021 / Published online: 21 May 2021

(c) The Author(s) 2021

\begin{abstract}
The measurement of displacement is an important factor to evaluate the stability of a retaining structure. In this paper, a large-scale retaining structure with a width of $70 \mathrm{~m}$ and a height of $6 \mathrm{~m}$ was monitored using 3-D laser scanning. Displacement mapping was proposed to globally monitor the entire retaining structure. The point cloud obtained immediately after the excavation was converted into the mesh, and the point clouds obtained on the second and seventh days after excavation were compared to the mesh using the Cloud to Mesh (C2M) comparison method. Since the C2M displacement can be underestimated in the inclined section of the sheet pile, after filtering using the azimuth and element angles automatically, only the flat sections of the sheet pile can be segmented from original point clouds collectively and consistently. The displacement mapping results identify not only the local behavior of the sheet pile, such as the bending point and the maximum displacement position, but also the global behavior, such as the expansion of the maximum displacement in the retaining structure. The results of the displacement mapping were confirmed through site investigation as well. In the displacement mapping result, the maximum displacement was found around rows 2 and 3 of the 37th sheet pile, and the analyzed result of the load cell installed on the anchor indicated that the anchor constructed in the 37th sheet pile shows the plastic behavior. It was established that other sheet piles are affected by the damage to the local anchor through the H-beam and the maximum displacement in the displacement mapping is expanded horizontally in a positive parabola shape. Therefore, it was confirmed that displacement mapping using laser scanning can complement existing monitoring techniques and can contribute to evaluating the behavior of a large-scale retaining structure during excavation.
\end{abstract}

Keywords Displacement mapping $\cdot$ Laser scanning $\cdot$ Point cloud $\cdot$ Retaining structure $\cdot$ Sheet pile $\cdot$ Anchor

\section{Introduction}

Reinforcement is necessary to prevent the collapse of the ground in an excavation site, and sheet piles are widely used to reinforce a retaining structure. Each sheet pile is connected with others by interlocking them to create the entire retaining structure. It is possible to prevent the collapse of

Hyungjoon Seo

hyungjoon.seo@liverpool.ac.uk

Yang Zhao

yang.zhao@xjtlu.edu.cn

Cheng Chen

cheng.chen19@student.xjtlu.edu.cn

1 Department of Civil Engineering, Xi' an Jiaotong Liverpool University, Suzhou 215000, China

2 Department of Civil Engineering and Industrial Design, University of Liverpool, Liverpool, UK the soil induced by excavation by driving the sheet pile into the ground before excavation. To minimize the displacement of the soil, reinforcement materials such as soil nailing or anchors are applied with the sheet pile as well. Various studies have been conducted on the interaction between anchors and sheet piles in field experiments using numerical analysis [3, 7, 29, 31, 37]. Seo et al. [27, 32] conducted a study that can improve the stability of the retaining wall while proposing a method which combines an anchor and soil nailing. Research on the behavior of the anchored sheet pile to establish the dynamic behavior of the ground is being conducted $[6,20]$. The anchor in the sheet pile minimizes the relaxation of the soil in terms of static or dynamic ground behavior. Therefore, anchors can also minimize the collapse of the ground when applying prestress in geotechnical structures $[26,28,29,31]$. Despite the use of various reinforcement methods, failure of the retaining structure can occur during excavation or due to various factors on the site [19]. 
Monitoring techniques are applied to determine the stability of the retaining structure during construction. Field monitoring is mainly used to measure the vertical direction and horizontal displacement of the ground behind the retaining structure through a borehole such as an extensometer, or an inclinometer and a tonal station can measure the displacement of a certain point where the target is installed $[1,2,17]$. However, since conventional monitoring methods can only monitor a specific area, the entire retaining structure cannot be monitored using these methods. It is difficult to determine in which section local damage will occur because the ground is excavated on a large scale in the retaining structure. Therefore, studies have been conducted to globally monitor entire retaining structures. Mani et al. [18] undertook construction management using the Building Information Model through photography acquired every day during construction. Hain and Zaghi [12] conducted inspection and monitoring of dry-stone masonry retaining walls using photogrammetry. In particular, many studies are being conducted to measure the displacement of infrastructure $[8,15,22]$ but photogrammetry has a low resolution when it comes to measuring the behavior of large-scale structures.

Laser scanning monitoring has higher accuracy than photogrammetry and can represent structures in three dimensions using numerous point clouds. Various studies have been conducted to improve the accuracy of laser scanning. Hack [10] studied laser metrology for precision measurements and inspection in industry. Hack [11] developed lasers and optical devices and introduced production technology. Dias-Lalcaca et al. [9] measured strain in electronic packages, using coherent fiber-bundles, with a laser-based instrument as well. Laser scanning has been widely applied to Building Information Modelling (BIM) because it is not highly accurate as a monitoring technique [4, 5]. Soga et al. [33] conducted a study on applying a smart monitoring technique that enables permanent and global monitoring of geotechnical structures. Laser scanning monitoring is being conducted on infrastructures [16, 23-25]. Studies in which laser scanning is used as a monitoring technique at excavation sites have been conducted [13, 35, 36]. Since laser scanning can monitor the deformation of the entire site due to excavation, studies have also been conducted to apply displacement monitoring to urban excavation [14, 34]. Recently, research on monitoring using laser scanning has been conducted to assess the stability of a retaining structure and it is necessary to improve the accuracy of this monitoring technique [27, $32,38]$. Errors can be generated depending on the surface condition of the structure because a shadowed area occurs in a rough or curved shape [23, 25]. Since the retaining structure monitored in this paper is composed of sheet piles, the surface is relatively flat compared to structures such as soil mixing walls and piles. Therefore, monitoring of this site was conducted using laser scanning to obtain point clouds to define the behavior of the retaining structure globally. After removing the effect of inclined section in the sheet pile in by data processing, the sheet pile was divided into 6 rows and 47 columns to allow displacement analysis to be performed on 251 elements of point clouds. It was possible to analyze the global behavior as well as the local damage of the retaining structure by performing displacement mapping for the entire retaining structure.

\section{Displacement mapping method}

Point cloud data can simulate the three-dimensional shape of a large-scale structure with a single laser scan. Therefore, it is possible to analyze the displacement in three dimensions for a large-scale structure. This paper proposed a displacement mapping method that can analyze the displacement behavior of large-scale structures using 3D point clouds. Laser scanning has been applied as a monitoring technique in limited infrastructures due to the low resolution and accuracy. It is also affected by applied construction methods. If data are collected by scanning the target structure, a proper point cloud comparison method needs to be selected for the distance calculation between the different point clouds. Since each point cloud comparison method is affected by shapes and factors such as roughness and curvature of the target structure, pre-treatment of the point cloud to minimize errors is required. The point cloud after pre-treatment has to be segmented into a number of elements for displacement mapping. The displacement is calculated by comparing the point clouds belonging to each element. The calculated displacement can be visualized by the displacement mapping, and the location of the maximum displacement and the expansion pattern of the displacement can also be evaluated using the displacement mapping. Finally, the cause of the displacement can be identified by an in-depth analysis of the location of excessive displacement. The framework of displacement mapping is shown in Fig. 1, and, in this paper, the displacement mapping of a retaining structure composed of sheet piles was performed following the framework.

\section{Site selection: retaining structure}

The site where the retaining structure was constructed has a total area of $5.6 \mathrm{ha}$, and large-scaled excavation was conducted. In this paper, a part of the retaining structure in the entire site was selected and monitored. As shown in Fig. 2a, the retaining structure is composed of sheet piles. Each sheet pile has a length of $17.5 \mathrm{~m}$, and each set of sheet piles is constructed at $1.5 \mathrm{~m}$ intervals. Before excavation, the sheet pile was constructed using a driving machine (see Fig. 2b). Anchors which were $21 \mathrm{~m}$ long were installed at $1 \mathrm{~m}$ below 
Fig. 1 Framework of displacement mapping
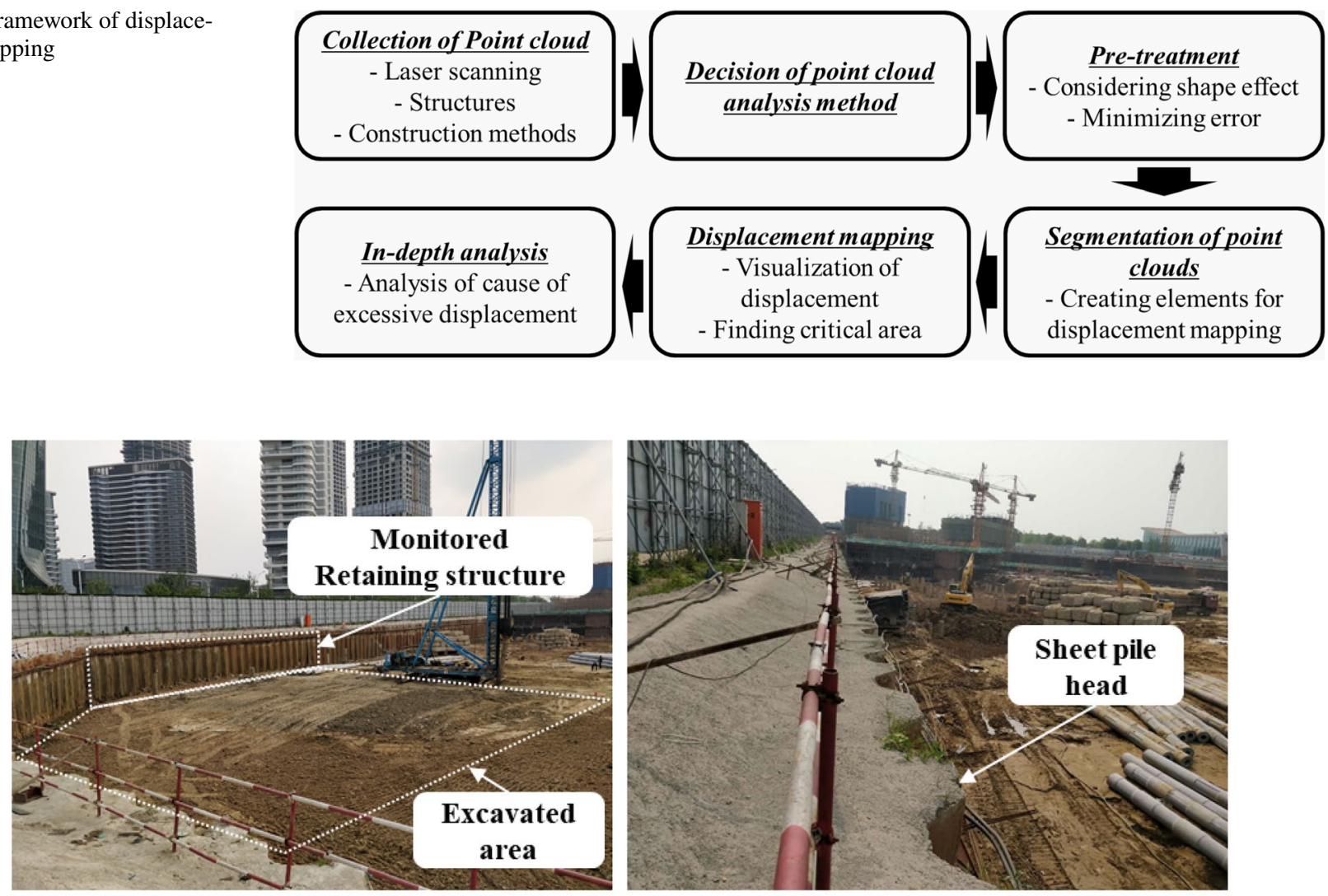

(a) Excavation site

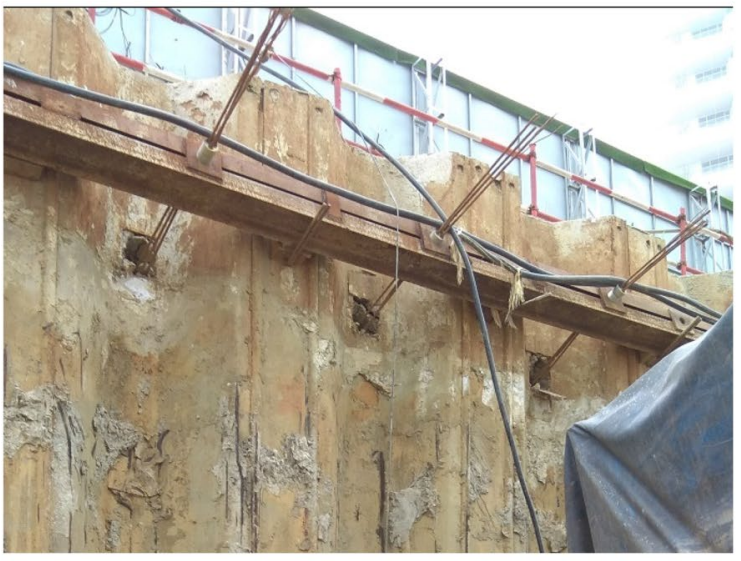

(c) Installed anchors

Fig. 2 Overview of retaining structure site

the top of the sheet pile. The movement of a retaining structure can be minimized, in terms of the displacement induced by excavation, by prestressing the installed anchors (see Fig. 2c). The excavation was started approximately $1 \mathrm{~m}$ below the ground surface after the installation of anchors (see Fig. 2d). The ground was excavated for 7 days by excavators. In this paper, laser scanning was conducted on the (b) Sheet piles of retaining structure

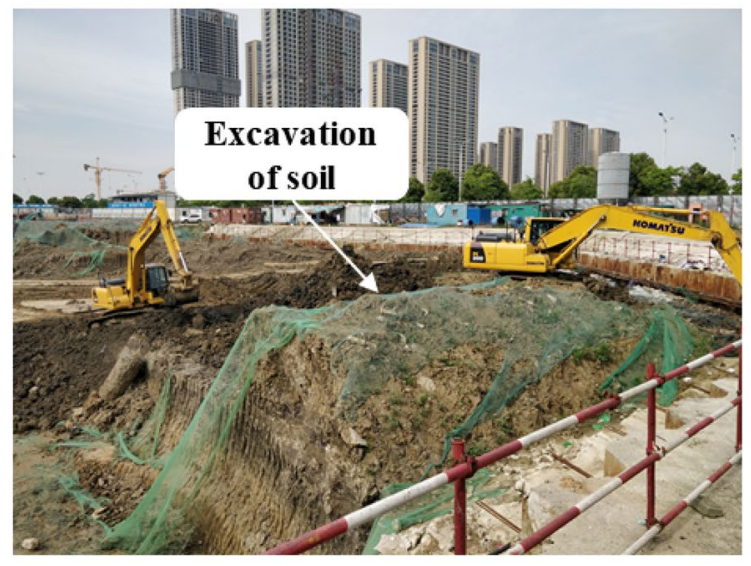

(d) Excavation of site day when excavation was completed, 2 days after excavation, and 7 days after excavation to evaluate the behavior of the retaining structure, composed of sheet piles, after excavation.

The retaining structure was divided into three sections: Sections A, B and C (see Fig. 3). The ground to be excavated was inclined as shown in Fig. 3a. A section of around $70 \mathrm{~m}$ 


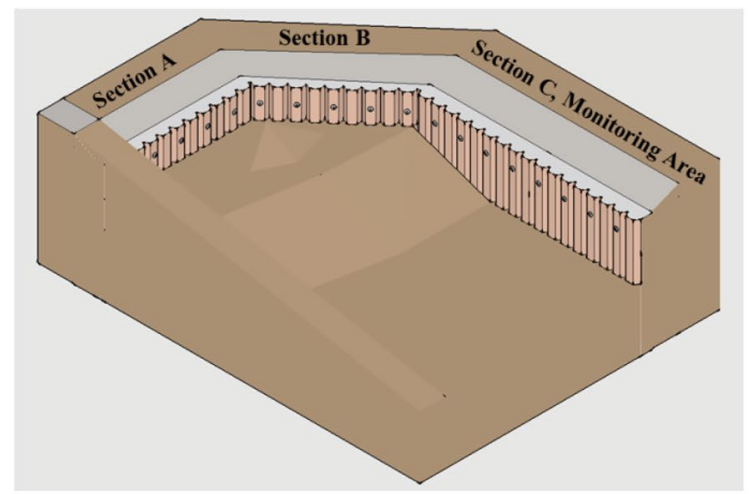

(a) Initial stage of ground

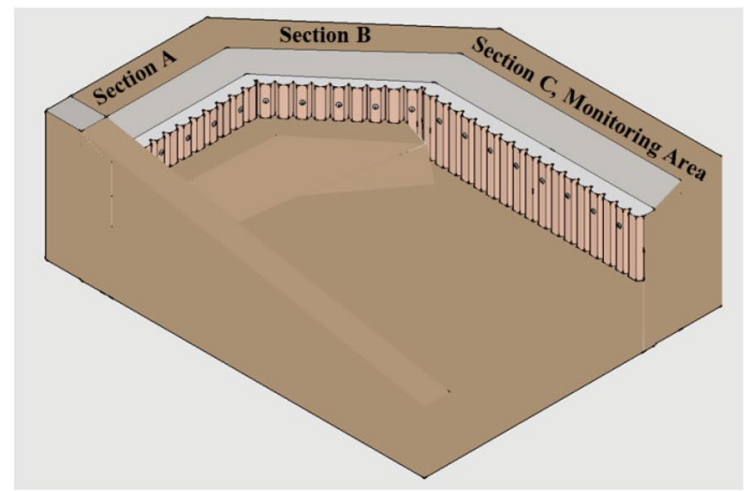

(b) Excavation of inclined gound

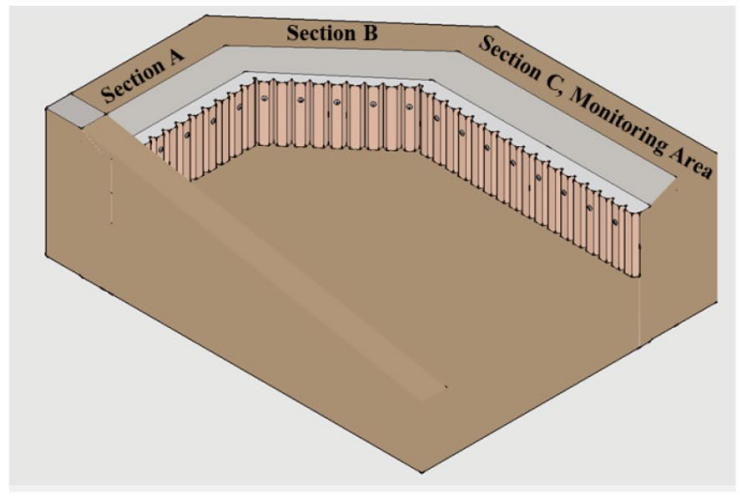

(c) Excavation of section A and B

Fig. 3 Excavation procedure

of the slope was located in Section $\mathrm{C}$ of the retaining structure, and this section was excavated first (see Fig. 3b). The remaining ground near Sections B and A of the remaining retaining structure was excavated later (see Fig. 3c). Since the length of the entire retaining structure including Section $\mathrm{C}$ was around $75 \mathrm{~m}$, bending in the horizontal direction could occur. Since Section $\mathrm{C}$ of the retaining structure was connected to Section A and Section B, confining stress could apply to the boundary between Section C and Section B. Therefore, displacement could be greater due to excavation in Section $\mathrm{C}$ as the distance from Section B increased. In this paper, the behavior of the retaining structure generated by such an excavation was predicted and then monitored.

\section{Methodology}

\subsection{Laser scanning}

The retaining structure of about $70 \mathrm{~m}$ in length and $6 \mathrm{~m}$ in height was monitored after excavation in this paper and the schematic diagram to show the monitoring plan is shown in Fig. 4a. Since laser scanning can allow three-dimensional monitoring of the entire structure, it is possible to obtain results like having millions of total stations. Therefore, the behavior of the entire structure was analyzed by displacement mapping using 3-D laser scanning. Laser scanning was performed in three locations: facing the retaining structure in front, on the excavated ground, and above Section A (see Fig. 4b). Scanning was performed at 3 different points in time, at three locations and hence 11 targets were installed to merge the collected point clouds into one coordinate system (see Fig. 4c). Since 11 targets were installed in different directions, even if an error occurred in 1 or 2 targets, the registration error of the point cloud can be compensated for by the other targets. The Leica P40 model laser scanner used in this paper, with accuracy range of $1.2 \mathrm{~mm}+10 \mathrm{ppm}$ over its full range. The resolution was set as $1.6 \mathrm{~mm}$ at $10 \mathrm{~m}$ for the field monitoring. Since a retaining structure composed of sheet piles has a flatter surface than a mixed structure of concrete and soil, such as a soil mixing wall (SMW), errors due to surface conditions could be minimized [23-25]. To 


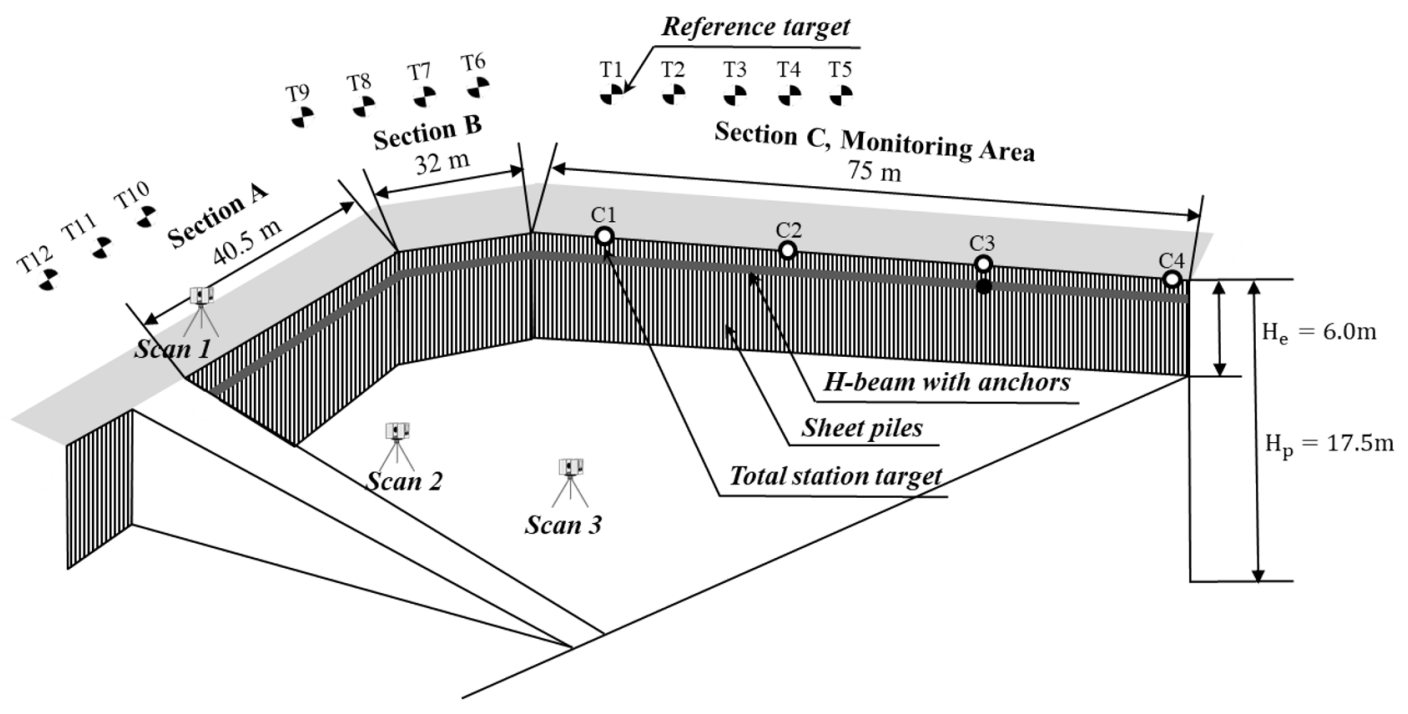

(a) Schematic diagram of monitoring for retaining structure

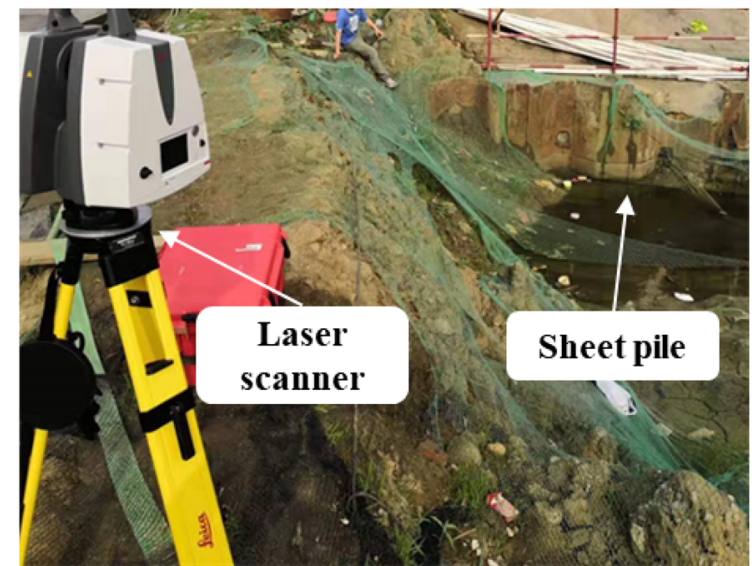

(b) Laser scanning

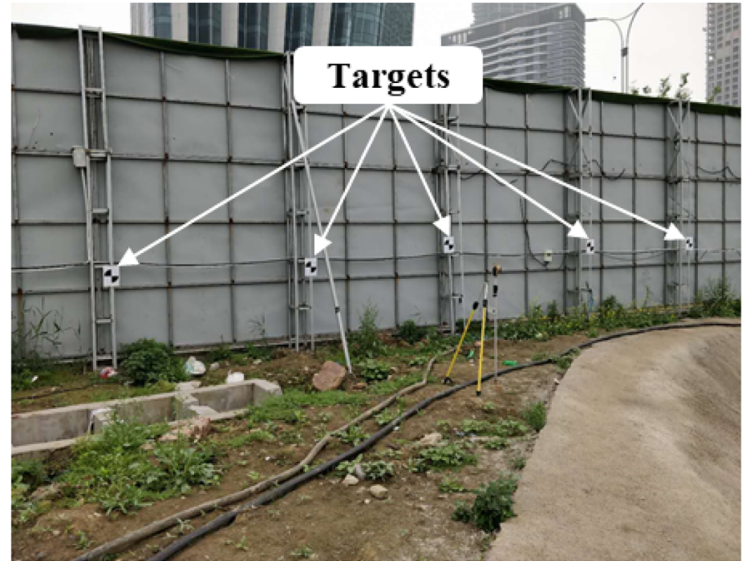

(c) Reference targets

Fig. 4 Monitoring technologies in retaining structure site

determine whether the laser scanning result was appropriate, four total station targets $(\mathrm{C} 1, \mathrm{C} 2, \mathrm{C} 3, \mathrm{C} 4)$ were installed on the heads of the sheet piles and compared with the displacement results calculated using the laser scanning data. The total station can only monitor specific points, but it can monitor during the entire construction period. The laser scanning aims to monitor the entire excavation surface exposed immediately after the excavation is completed, since it is possible to monitor the entire retaining structure but it is constrained by the monitoring time or site conditions. A set of sheet piles was installed at $1.5 \mathrm{~m}$ intervals with other sheet piles so that the point clouds of sheet piles were analyzed by splitting those at $1.5 \mathrm{~m}$ intervals in the horizontal direction. The four targets of the total station corresponded to numbers S9, S24, $\mathrm{S} 37$, and S47, in the sheet piles and the analysis position was calculated based on the first sheet pile (S1). Each anchor was constructed one by one for each sheet pile set, and a load cell was installed on the anchor constructed at S37 to measure the load variation of the anchor due to excavation. The detailed location of the installed monitoring system is shown in Table 1.

\subsection{Data analysis methods}

The specific area of an object can be shadowed depending on the location of the laser scanner and site conditions and hence laser scanning needs to be performed in various positions to minimize the shadow effect. As shown in Fig. 5a, since each surface of the sheet pile has a different angle, a surface can be obscured depending on the angle between the scanner and the structure. The resolution also varied depending on the distance between the scanner and 
the structure. In the case of large-scale structures, such as the retaining structure monitored in this paper, the resolution of areas located far from the scanner decreased proportionally with the distance. Therefore, laser scanning was performed at three locations to minimize the shadowed area in this paper. Each point cloud with a different local coordinate system can be represented in one global coordinate system using 11 reference targets. Figure $5 \mathrm{~b}$ shows an example of the point cloud acquired in this paper, and it can be seen that the entire retaining structure was covered by the laser scanning.
To determine the distance between point clouds, Cloud to Cloud (C2C) and Cloud to Mesh (C2M) methods are widely used. The $\mathrm{C} 2 \mathrm{C}$ method provides an average value by calculating the distance between an individual point in one point cloud and the closest point among points in another point cloud. In the $\mathrm{C} 2 \mathrm{M}$ method, an average distance is provided by calculating the distance between a mesh created from one point cloud and points in another point cloud. As shown in Fig. 6, two point clouds scanned in different periods can be compared in laser scanning monitoring. If the analysis is performed by the $\mathrm{C} 2 \mathrm{C}$ method, nearest points between

Table 1 Location of monitoring system

\begin{tabular}{lllllll}
\hline Sheet pile number & S1 & S9 & S24 & S37 & S47 & - \\
Distance from S1 (m) & 0 & 12.0 & 34.5 & 54.0 & 69 & \\
Total station No. & - & C1 & C2 & C3 & - & C4 \\
Distance from S1 (m) & & 12.6 & 35.1 & 54.6 & & 74.6 \\
Load cell of Anchor & - & - & - & AC1 & - & - \\
Distance from S1 (m) & & & & 54.0 & & \\
\hline
\end{tabular}

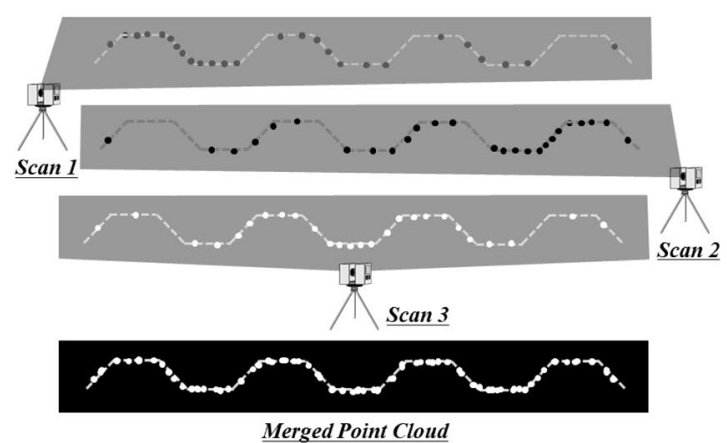

Merged Point Cloud

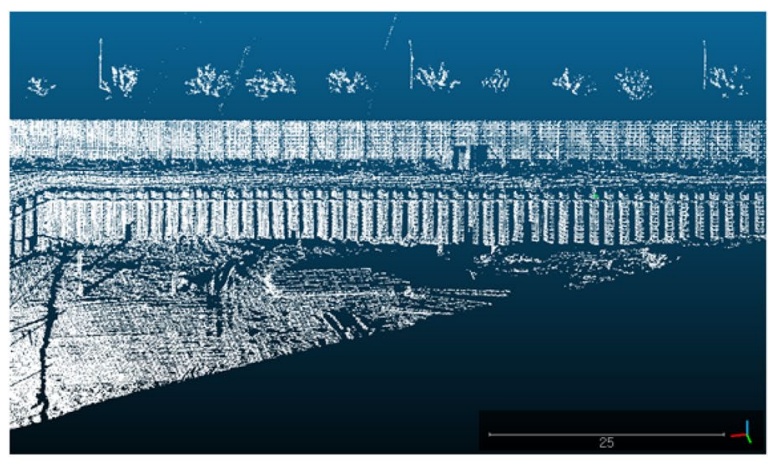

(b) Raw data of Point clouds

(a) Merging point clouds

Fig. 5 Registration of point clouds

Fig. 6 Selection of analysis method

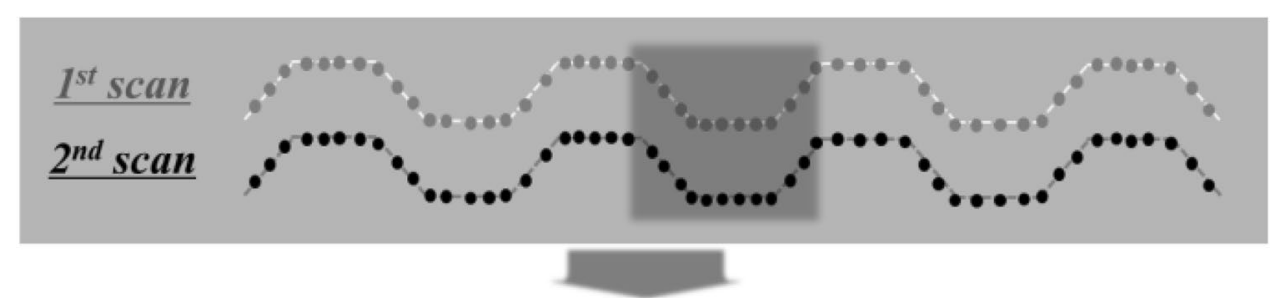

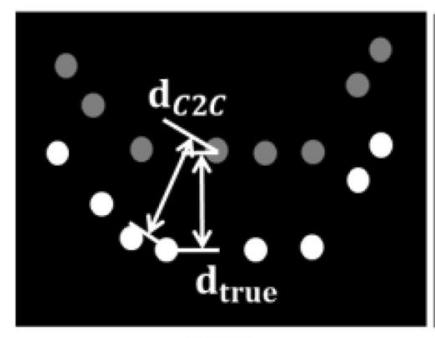

$\underline{C 2 C}$

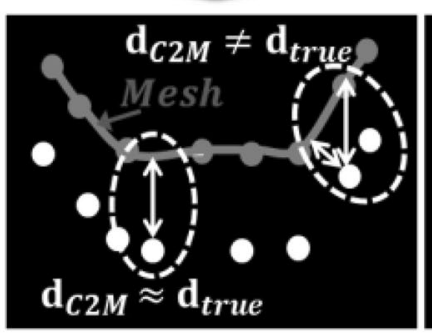

$\underline{C 2 M}$

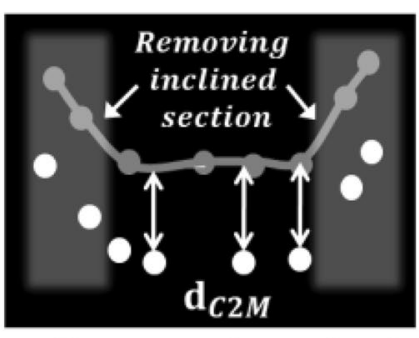

Proposed method 
difference point clouds are directly compared, so that the movement of the actual structure can be over- or underestimated. If the resolution of the point cloud is not higher than the expected displacement, the results evaluated by the $\mathrm{C} 2 \mathrm{C}$ method are dominant on the resolution of the point cloud. However, since the C2M distance is calculated after meshing a point cloud, the displacement evaluation error can be reduced more than that evaluated by the $\mathrm{C} 2 \mathrm{C}$ method. Therefore, it is possible to minimize errors using the $\mathrm{C} 2 \mathrm{M}$ method due to resolution in field monitoring of large-scale structures such as a retaining structure. However, if the direction in which the displacement occurs is not perpendicular to the surface of the structure, such as the inclined surface of the sheet pile in Fig. 6, the C2M distance can lead to underestimation of the actual displacement because the points are compared to the nearest mesh for the distance calculation. Therefore, data processing was performed to remove the inclined section of the sheet pile so that the error induced by the inclined section of the sheet pile is not reflected in the displacement calculation for the sheet pile.

\subsection{Pre-treatment of point clouds}

Since both inclined and flat sections are included in a set of sheet piles, in-depth analysis is needed to define the effect of the inclined section in $\mathrm{C} 2 \mathrm{M}$ analysis. The $\mathrm{C} 2 \mathrm{M}$ distance distribution patterns in the inclined section and the flat section are defined by comparing the point clouds of the sheet pile before and after excavation. The point cloud expressed in red in Fig. 7a is the collected point cloud immediately after excavation, and the point cloud expressed in white is the point cloud collected 7 days after the excavation. Figure $7 \mathrm{~b}$ shows the distribution of points in terms of the $\mathrm{C} 2 \mathrm{M}$ distances for inclined and flat sections. In the results based on calculating the $\mathrm{C} 2 \mathrm{M}$ distance by meshing the point cloud obtained immediately after excavation, the flat section has a mean $\mathrm{C} 2 \mathrm{M}$ distance of $4.277 \mathrm{~mm}$, showing a difference of about $0.03 \mathrm{~mm}$

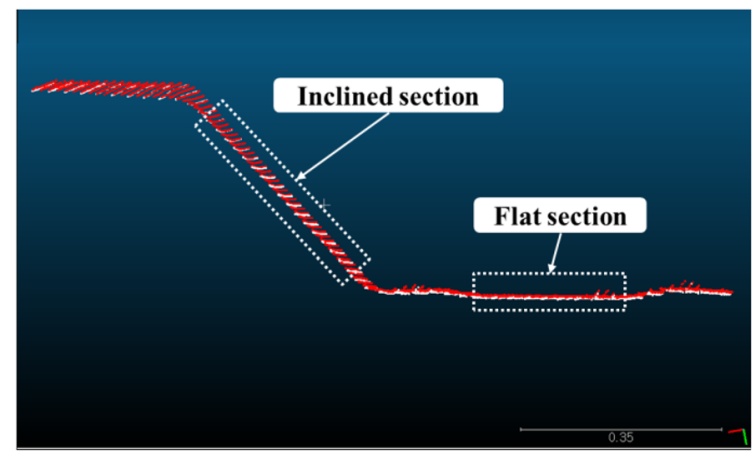

(a) Two sections in point clouds

Fig. 7 Effect of inclined section in C2M distance calculation from the total station result. However, the mean $\mathrm{C} 2 \mathrm{M}$ distance of the inclined section is $1.996 \mathrm{~mm}$, which is about $2.25 \mathrm{~mm}$ smaller than the displacement measured by the total station. This is because the direction in which the displacement occurs in the inclined section is not perpendicular to the surface of the inclined section. The C2M distance calculated in the inclined section can lead to underestimation of the actual displacement, and hence data processing was performed to remove the point cloud of the inclined section in this paper.

Before performing displacement mapping of the point cloud, it was necessary to undertake data processing for the point cloud. As illustrated in Fig. 7, the inclined section and the flat section have to be separated in the sheet pile and then the inclined section has to be removed to minimize the displacement calculation error caused by the inclined section. Although it is possible to divide the point cloud manually, to divide all point clouds for sheet piles consistently, an automatic segmentation method was proposed for this paper. As shown in Fig. 8a, the area with the sheet pile can be segmented from the original point cloud. The point cloud of the sheet pile has locally angled regions as well as inclined sections. Therefore, the global azimuth angle of the point cloud was analyzed. As shown in Fig. 8b, the distribution of points is concentrated on two peaks. Since the azimuth angle representing the flat area of sheet pile is distributed mainly around $78.5^{\circ}$, the global azimuth angle was filtered in consideration of an error of $\pm 5^{\circ}$ from $78.5^{\circ}$. To remove the inclined section described in Fig. 7, the pattern of the elevation angle was identified, and points representing the flat section were distributed around $0^{\circ}$; the points representing the inclined section show a pattern in which the elevation angle increases or decreases depending on the position (see Fig. 8c). Density-based spatial clustering of applications with noise (DBSCAN)-clustering was used to separate the filtered point cloud into individual sheet pile elements [21]. Therefore, filtering was performed in consideration of an error of $\pm 5^{\circ}$ from $0^{\circ}$. The local curvatures

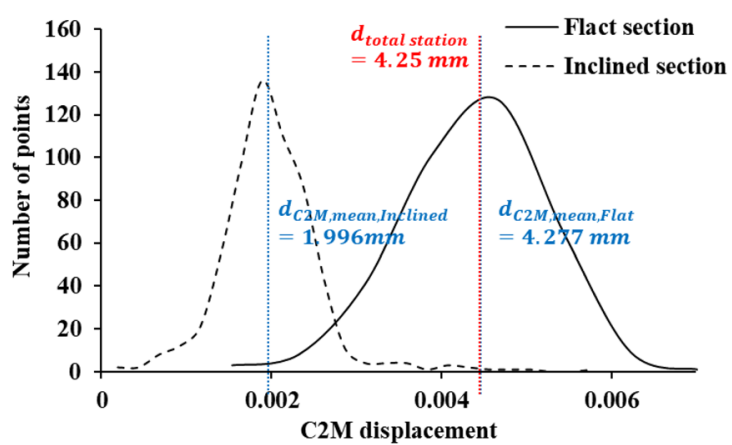

(b) C2M distance histograms of two sections 

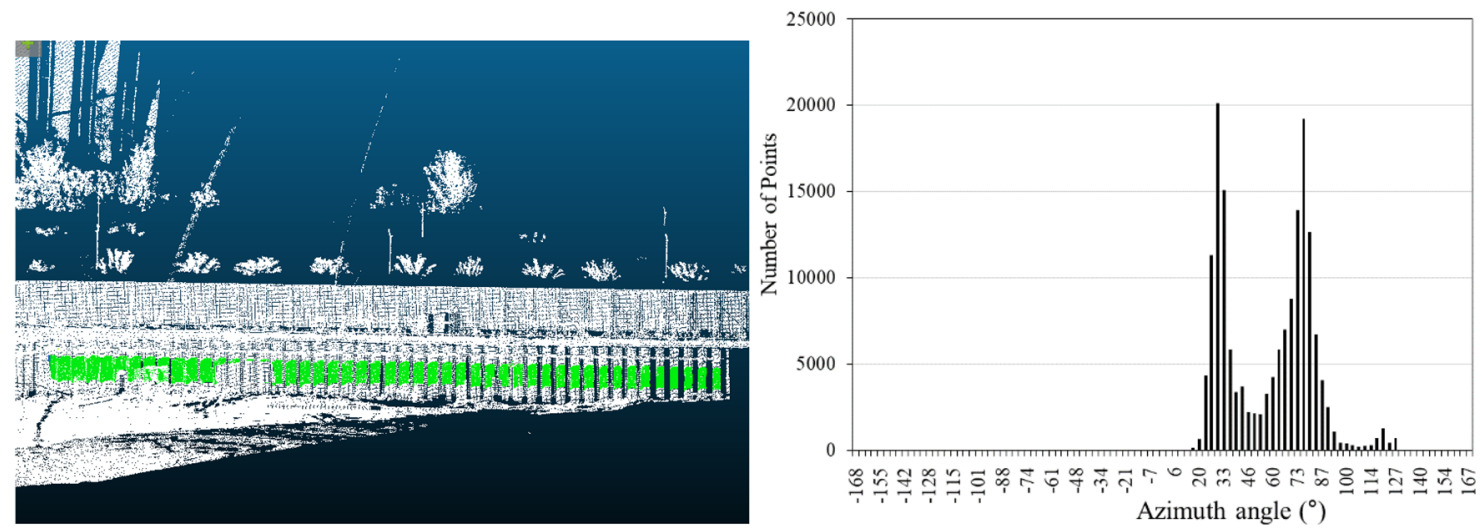

(a) Point cloud representing original group of sheet piles (b) Azimuth angle distribution

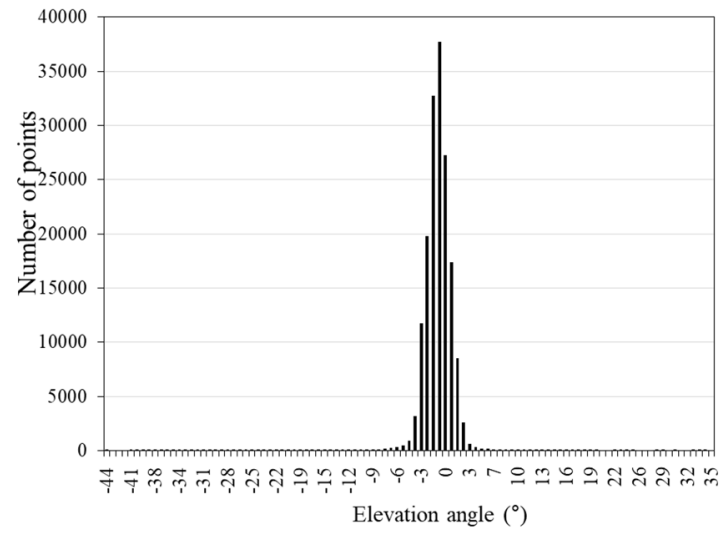

(c) Elevation angle distribution

Fig. 8 Data processing to remove inclined section and local curvature

and inclined sections were filtered using the azimuth and elevation angles, and the results are shown in Fig. 8d.

\section{Displacement mapping of retaining structure}

\subsection{Segmentation of sheet pile elements}

Laser scanning can express a three-dimensional shape with numerous points so that it can compensate for the shortcomings of the conventional monitoring system, which can cover the local area or specific points. In this paper, a displacement mapping method is proposed in order to analyze the displacement of an entire structure with a 3-D point cloud collected during field monitoring. The flat sections of the 47 sheet piles automatically divided in Fig. 8 are shown in Fig. 9a. The point cloud collected 7 days after excavation was unable to scan certain areas located at the bottom of the sheet piles in columns 13 to 16 with any scanning angle because the anchor installation machine was on site during scanning (see Fig. 9b). As shown in Fig. 9c, all sheet piles were divided into six columns to create the elements necessary for the displacement mapping. The center of the first row, corresponding to the head of the pile, was located about $0.35 \mathrm{~m}$ below the ground surface. Elements including anchors under the pile head, which were approximately $1.5 \mathrm{~m}$ long, were excluded from analysis. The remaining five rows were divided into $1 \mathrm{~m}$ intervals as shown in Fig. 9c. The number of elements divided for displacement mapping was 251, and point clouds and C2M distances obtained on the second and seventh days after excavation were calculated based on the mesh converted from the point cloud obtained immediately after excavation from each element.

Figure 10 is an example to show the C2M analysis for the elements of a sheet pile. Figure 10a shows an example where the displacement that occurs is about $16 \mathrm{~mm}$, and this element is located in row 2 and column 36 . The mesh converted from the point cloud obtained immediately after the excavation shows a noticeable difference from the points obtained 


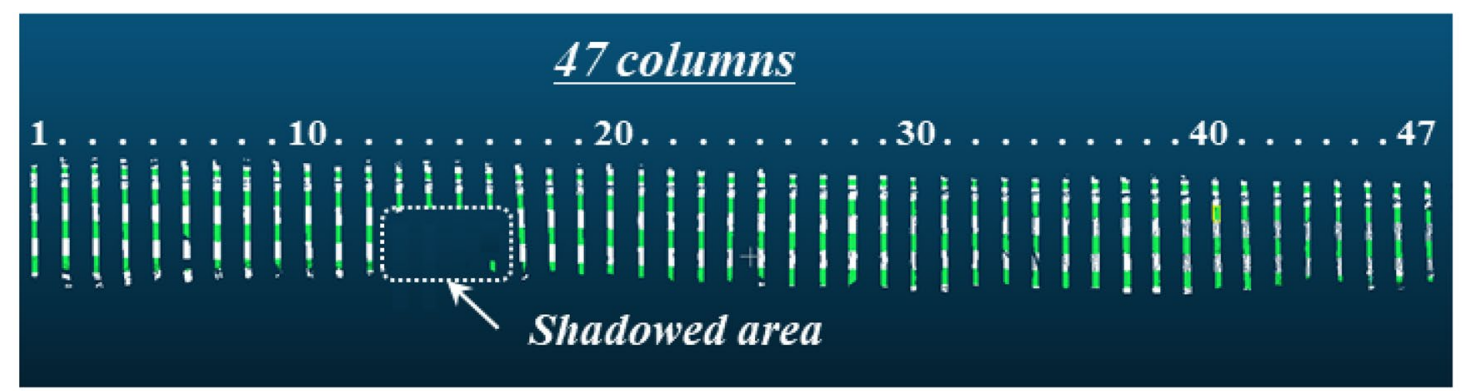

(a) Divided elements for displacement mapping
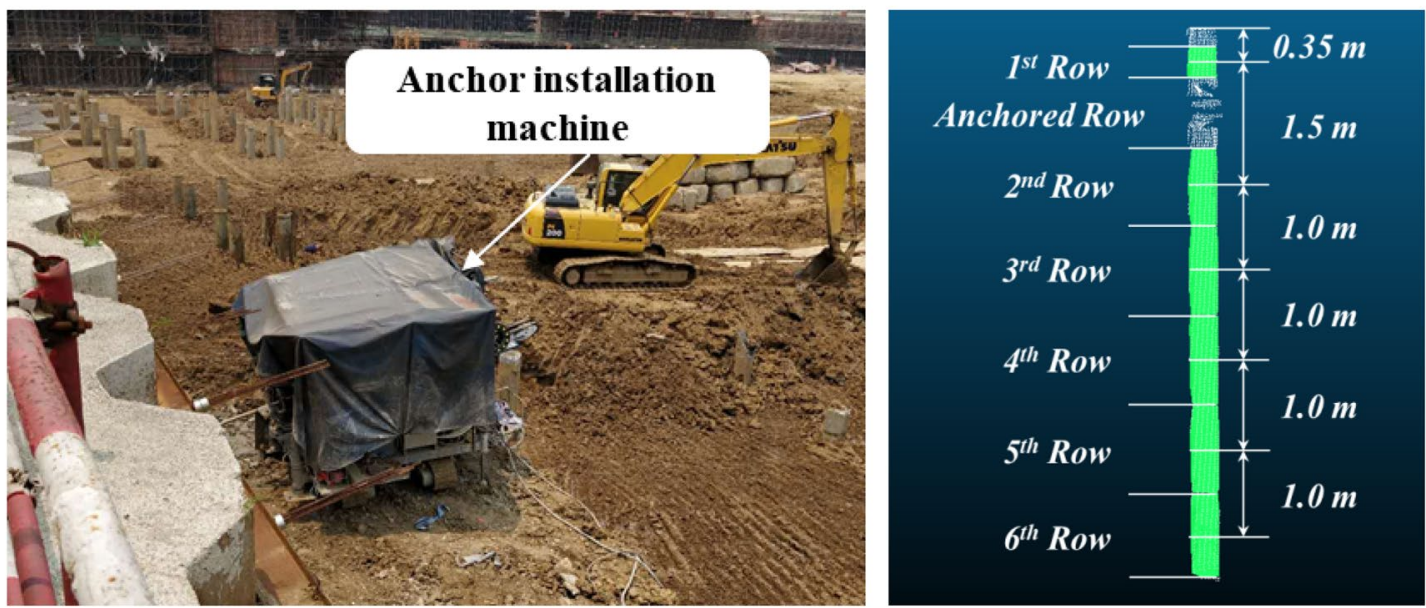

(b) Shadowed area due to anchor installation (c) Divided element in a sheet pile

Fig. 9 Divided point clouds for displacement mapping

Fig. 10 Examples of mesh to cloud comparison at different elements of sheet pile (row, column)

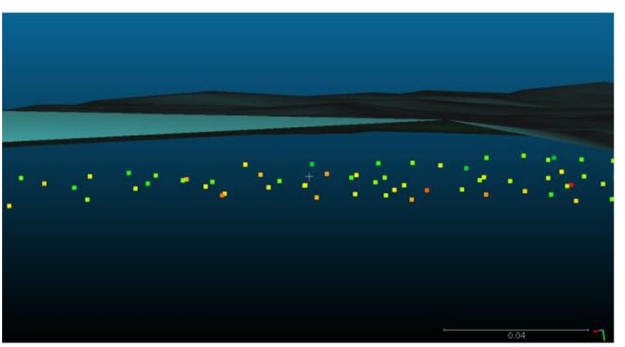

(a) Mean C2M distance: $15.97 \mathrm{~mm}(2,36)$

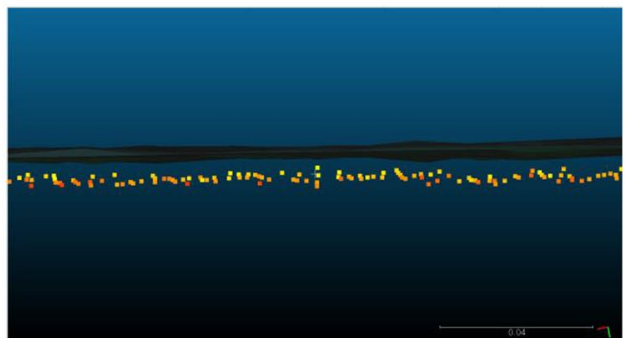

(c) Mean C2M distance: $8.93 \mathrm{~mm}(2,26)$

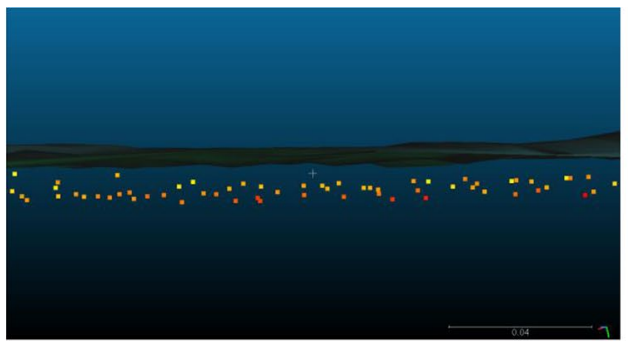

(b) Mean C2M distance: $12.81 \mathrm{~mm}(1,28)$

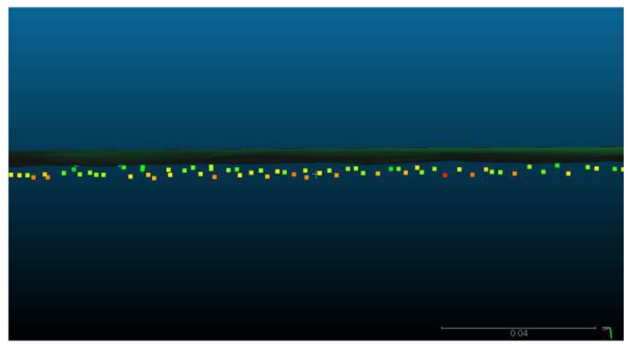

(d) Mean C2M distance: $4.85 \mathrm{~mm}(1,17)$ 
7 days after the excavation. Since the sheet pile has a flat surface and less curvature than a concrete structure, such as an SMW, it can be seen that the actual sheet pile is clearly expressed as a mesh. Figure 10b shows the case where the displacement that occurs is about $12.8 \mathrm{~mm}$ with the element located in row 1 and column 28 . It can be seen that the spacing between the mesh and the points is clearly checked at the $0.1 \mathrm{~m}$ view scale. Figure 10c shows the mesh and point comparison of the elements located in row 2 and column 26 , and the displacement is about $8.93 \mathrm{~mm}$. Although the points are still located in front of the element, the distance between the mesh and the point has decreased significantly. Figure 10d shows the comparison of the meshes and points of the elements located in row 1 and column 17, and the displacement is about $4.85 \mathrm{~mm}$. It can be seen that the mesh and the points are closely attached compared to the other point cloud comparisons. Each element shows a similar pattern to the examples in Fig. 10, and when the point cloud from 7 days after excavation is compared with the mesh of the point cloud obtained immediately after excavation, it is verified that the $\mathrm{C} 2 \mathrm{M}$ results not only have a tendency according to the position of the element, but also clearly express the excavation displacement.

\subsection{Verification of the monitoring availability of laser scanning}

To find out whether laser scanning is applicable as a displacement monitoring technique for the retaining structure, the analysis results of the total station, which are generally used to measure the displacement of the retaining wall, were compared with the results of laser scanning. Since the total station was monitored over the entire construction period at each target point, temporal trends were compared based on the results of the total station. Since the entire area of the retaining structure could be monitored by laser

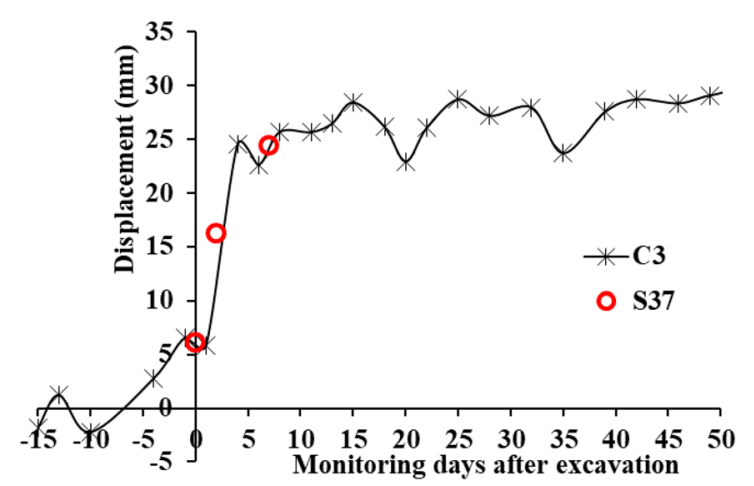

(a) Displacement variation with time at around S37 scanning, the spatial trend was compared with the results for the total station based on the results of laser scanning. The accuracy of the total station used in this site was $1 \mathrm{~mm}$. Figure 11a shows a comparison of the total station and laser scanning results according to the monitoring date at sheet pile location S37. Since laser scanning can scan the excavation surface immediately after the completion of excavation, the monitoring timing was undertaken later than of the scanning for the total station. The total station monitored during the entire excavation period from before the excavation, and hence the displacement on day 0 of laser scanning, shifted to $6.19 \mathrm{~mm}$, which is the displacement measured by the total station. The total station results show that the displacement increases dramatically immediately after excavation, and converges after 4 days. The maximum displacement was $32.97 \mathrm{~mm}$, which was about $0.55 \%$ of the excavation height $(6.0 \mathrm{~m})$. When comparing the results with laser scanning, it can be seen that the trend is almost the same. In this paper, total station monitoring was performed using four targets $(\mathrm{C} 1, \mathrm{C} 2, \mathrm{C} 3, \mathrm{C} 4)$ installed in the section of the retaining structure where the laser scanning was performed. Figure $11 \mathrm{~b}$ shows the $\mathrm{C} 2 \mathrm{M}$ distance of the point cloud and the displacement calculation result for the total station corresponding to the pile head at the first column of the sheet pile. As shown in the results for the laser scanning, the displacement was less than about $5 \mathrm{~mm}$ until around $25 \mathrm{~m}$, then the displacement increased from $25 \mathrm{~m}$ gradually and then decreased again after the maximum displacement occurred at about $54 \mathrm{~m}$. The tendency of the displacement to increase or decrease according to each position is similar to the results for the total station. The displacements at points $\mathrm{C} 1, \mathrm{C} 2$, and C3, where the total station targets were installed, differed from the results for the laser scanning by $0.61 \mathrm{~mm},-0.29 \mathrm{~mm}$, and $1.99 \mathrm{~mm}$, respectively. Therefore, it was verified that the laser scanning and point cloud comparison method

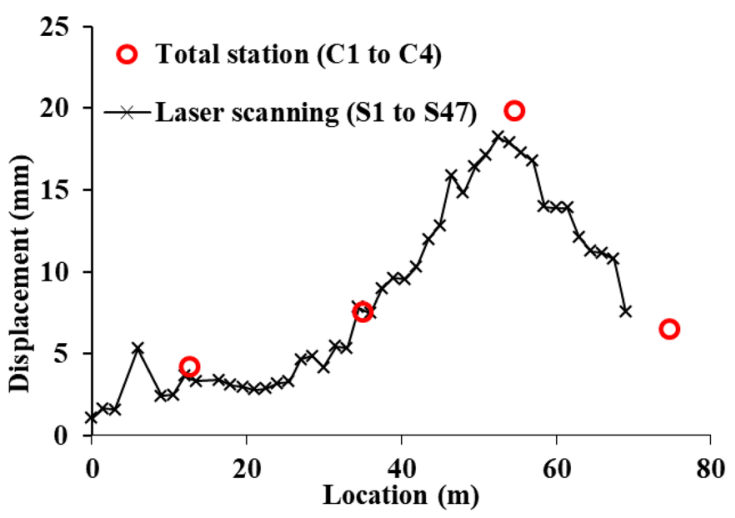

(b) Displacement comparison along sheet piles

Fig. 11 Comparison results between laser scanning and total station 
used in this paper are appropriate for use as a monitoring system to define the behavior of a retaining structure composed of sheet piles, and hence point cloud analysis was conducted for the entire retaining structure.

\subsection{Displacement mapping using C2M method}

While conventional monitoring techniques have been able to measure the displacement of a specific point, laser scanning can monitor the entire structure with numerous points. Therefore, in this paper, C2M displacement analysis was performed on the 251 elements of the sheet pile point clouds corresponding to the retaining structure, and the shadowed area was excluded from the analysis. Figure 12a shows the results of displacement mapping for the retaining structure by comparing the point cloud obtained immediately after the excavation with the point cloud obtained 7 days after the excavation. The displacement mapping result clearly shows the displacement expansion pattern of the retaining structure caused by the excavation. The maximum displacement was $18.48 \mathrm{~mm}$ in row 3 and column 37. The elements where the displacement is larger than $17 \mathrm{~mm}$ are from columns 35 to 38 in row 1 , column 37 column in row 2 , and column 27 in row 3 , respectively, and there is a positive parabolic

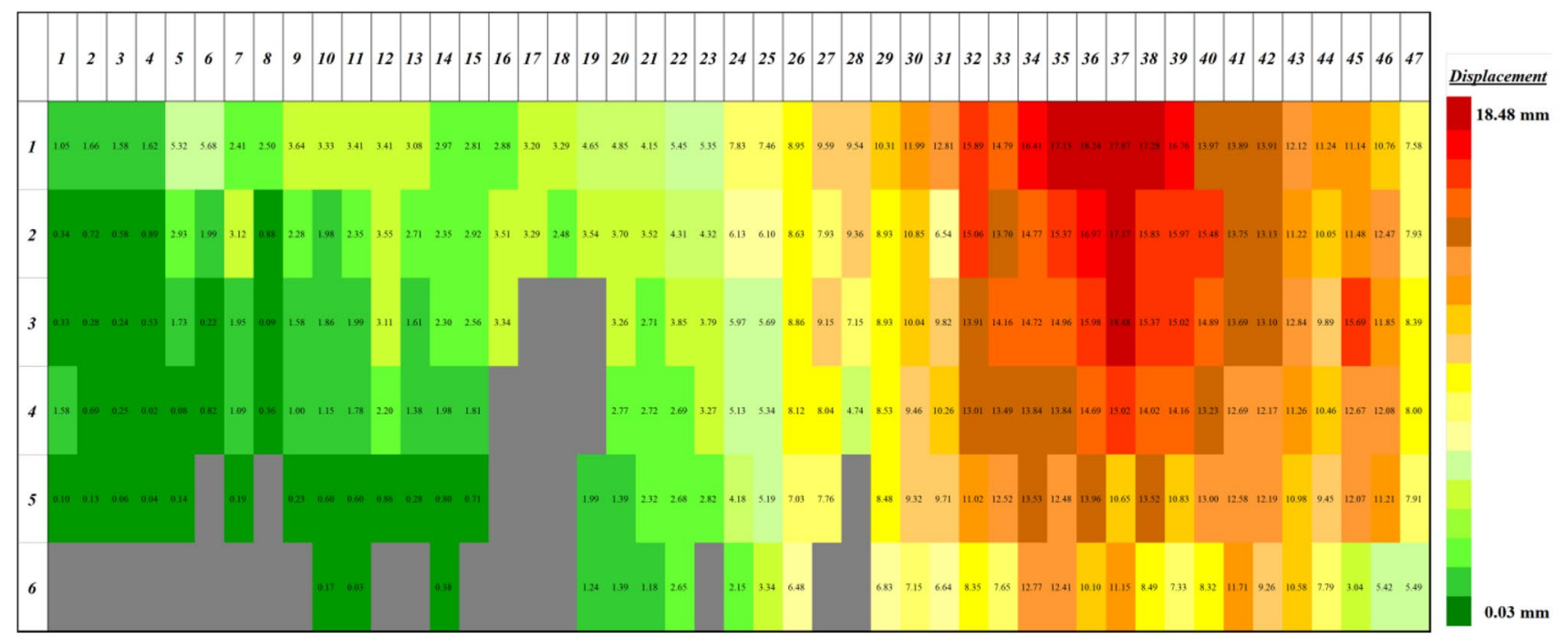

(a) Displacement mapping of sheet piles in retaining strucuture

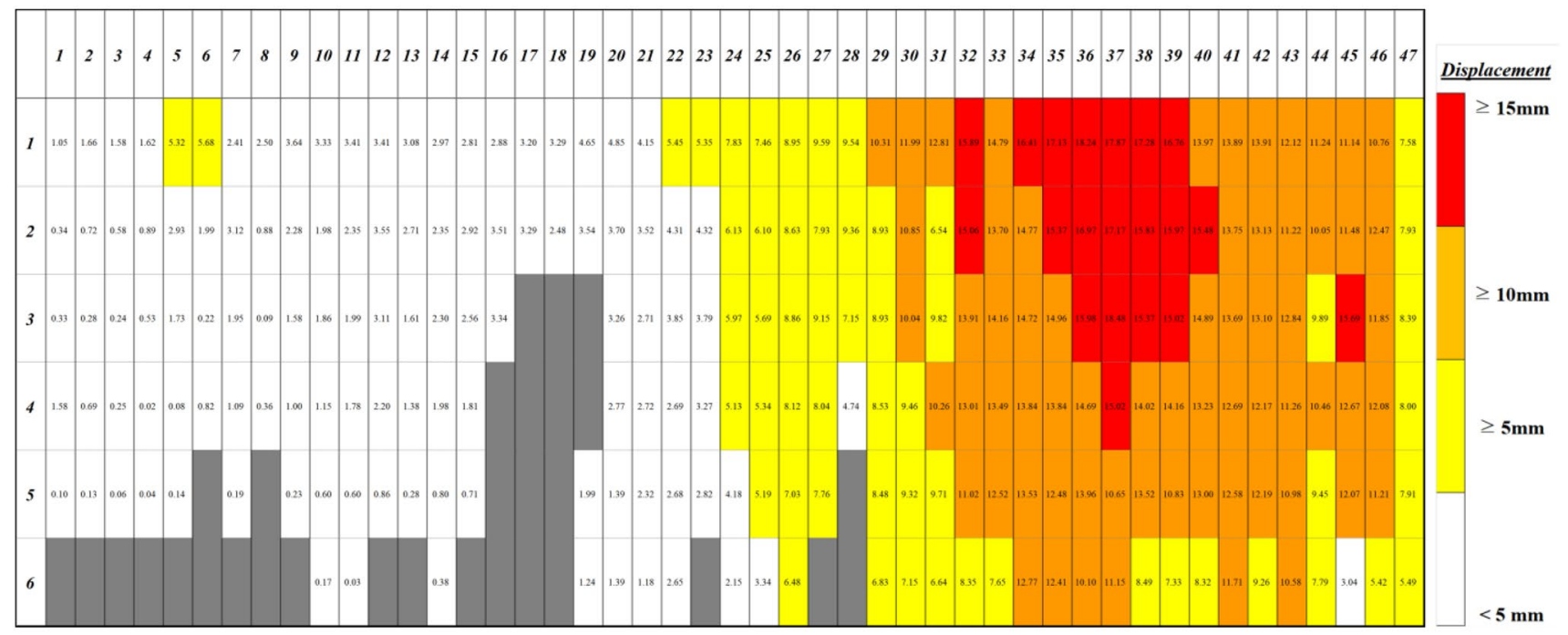

(b) Shape of movement (displacement $\geq 10 \mathrm{~mm}$ )

Fig. 12 Global behavior of the retaining structure expressed by displacement mapping 
displacement pattern that decreases as the elements descend from the pile head. The width of the positive parabola is wider with a decrease in the displacement, indicating that the retaining structure protrudes in the horizontal direction. Most of the results for row 2 shows that the displacement is small or similar to row 3, but the displacement is smaller than in row 1. Anchors and H-beams are installed between the first and second rows and the skin friction of the anchors is mobilized as displacement increases, and hence confining stress against to the retaining structure is operated by the fixed points of anchors on the beam. Therefore, it is found that the movement of the sheet piles is restricted by the installed anchors according to the displacement mapping results. Displacement decreases dramatically as the position of the sheet pile approaches Section B. The displacement is mostly controlled within $5 \mathrm{~mm}$ if the column number is lower than S21. It can be seen that the displacement behavior is controlled by the horizontal earth pressure of the ground itself because Section B is located at the corner and the ground in Section A is perpendicular to Section C. To define the expansion of the maximum displacement occurring at S37 in the horizontal direction, the displacement mapping result, re-evaluated with a displacement scale interval of $5 \mathrm{~mm}$, is shown in Fig. 12b. The area where displacement of more than $15 \mathrm{~mm}$ has occurred affects up to 4 rows in a narrow parabolic area. The area where the displacement of more than $10 \mathrm{~mm}$ is further expanded and it is located within columns 29 to 46 , and the area where the displacement of more than $5 \mathrm{~mm}$ is expanded to column 22 . As shown in the displacement mapping result in Fig. 12, the maximum displacement generated at line 37 of the sheet pile is expanded out in a parabolic form in the horizontal direction. The displacement mapping shows that it is possible to evaluate the global and local behaviors of the retaining structure due to excavation.

The sheet piles are connected to each other by interlocking so that generally, they behave together, but since each sheet pile is not perfectly connected, sheet piles that behave independently can be found in the displacement mapping. Therefore, analysis needs to be performed to define the behavior of sheet piles that behave independently. Detailed analysis was performed on each row and column of sheet piles, and the results are shown in Fig. 13. Figure 13a shows the horizontal displacement variation for each row. It can be seen from the displacement results that large bending occurs in the horizontal direction around sheet piles S37 and S22. In the results for horizontal displacement for each row, row 1 has a displacement greater than that of other rows in most elements. Rows 2 and 3 have a similar pattern due to the confining effect of the anchors, and rows 3, 4 and 5 show a pattern in which the displacement decreases with the increase of row number. Figure $13 \mathrm{~b}$ shows the displacement variation in the vertical direction, which is analyzed to clarify the reduction pattern in each row. In the results for columns 10, 21, 25, and 30 , the displacement decreases linearly from rows 2 to 5 . The displacement in row 2 decreases more rapidly than that in the first row due to the influence of the anchor and H-beam. The displacement also decreases more rapidly in the 6th row than that in the 5th row, and it can be seen that the bottom of the pile has not moved due to the unexcavated ground. Therefore, it was established that large banding occurs at the boundary between the unexcavated ground and the bottom of the sheet pile. Sheet pile S37 shows a slightly different result to that for other sheet piles. Most of the sheet piles showed maximum displacement at the pile head and this then decreased when from the head of the pile to the bottom. But in S37, there are a few reductions in displacement in row 2 , and row 3 has the largest displacement among all the elements. The maximum displacement thus generated causes positive parabolic-shaped displacement behavior in the retaining structure. Displacement mapping through laser scanning can define the local behavior of each sheet pile as well as
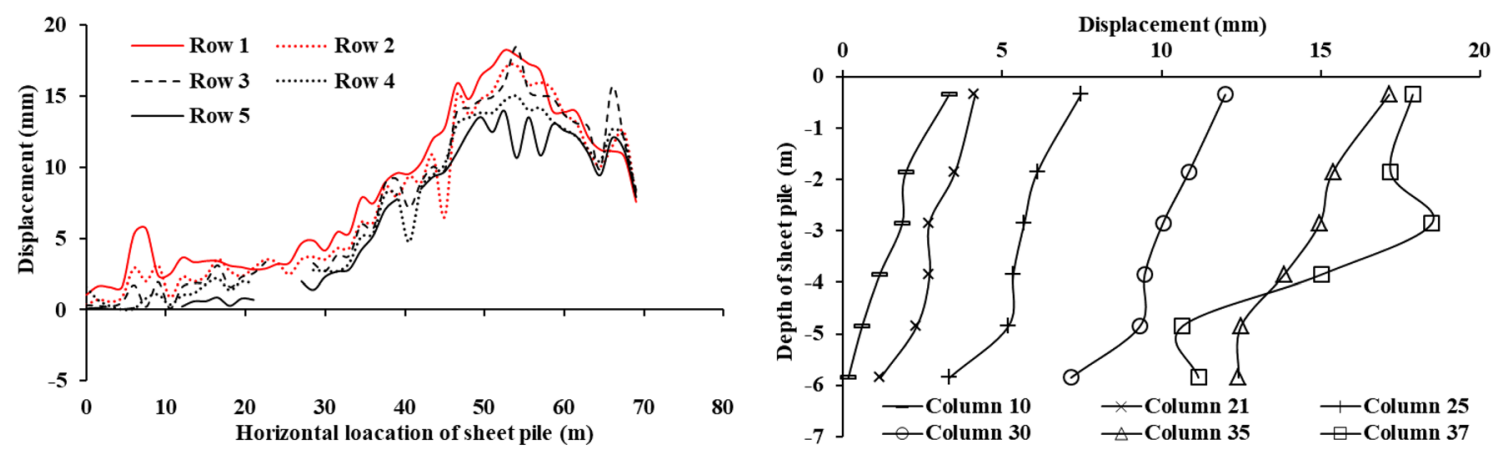

(a) Displacement variation in horizontal direction

(b) Displacement variation with depth

Fig. 13 Displacement variation of sheet pile 
the overall displacement behavior of an entire retaining structure. Displacement mapping also indicated that excessive displacement occurred in a specific sheet pile, and thus how this sheet pile affects the overall behaviour of the retaining structure can be defined. Therefore, the displacement mapping presented the basis for in-depth analysis of the behavior of sheet pile S37, which caused movement across the entire retaining structure.

\subsection{In-depth analysis of damaged section detected by displacement mapping}

It has been established that a large displacement occurred around the S37 sheet pile according to the displacement mapping results and field investigation. A load cell was installed on the anchor face constructed in S37 to continuously measure the load variation over time. At this site, about $95 \mathrm{kN}$ of prestress was applied during anchoring to reduce the stress release of the soils due to the excavation. Three PC strands with a diameter of $15.2 \mathrm{~mm}$ were used as anchor reinforcements, as shown in Fig. 14a. The length of the anchor was $21 \mathrm{~m}$, and grouting was injected up to about $13 \mathrm{~m}$ from the tip of the anchor. The anchor was installed into four different soils as shown in Fig. 14b. Since each anchor was connected in a horizontal direction by the H-beam, they all had the same behavior as each other. Therefore, if one anchor is damaged, other sheet piles are affected through the H-beam, and damage in one anchor can be compensated for by the resistances of other anchors as well. A total of 43 drainage wells were installed and excavation was carried out under drainage conditions. The detailed drainage wells layout is shown in Fig. 14c.

To determine the stability of the anchor installed in S37, the ultimate resistance of the anchor has to be evaluated. The stability of the anchor can be identified by comparing the calculated ultimate resistance force and the data of the load cell installed on the anchor. The ultimate skin friction of the anchor can be calculated using the soil properties presented in Fig. 14b. If it is assumed that the anchor installed in S37 has excessive displacement, the ultimate skin friction

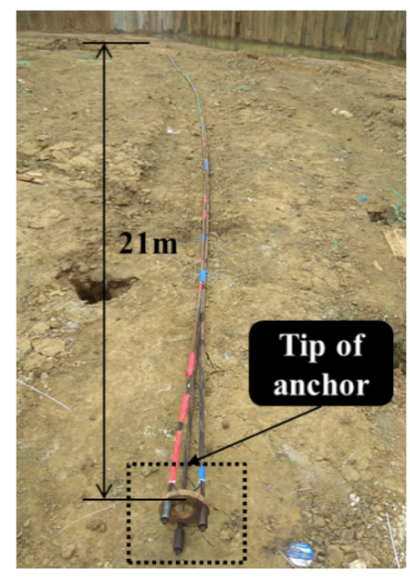

(a) Installed anchor

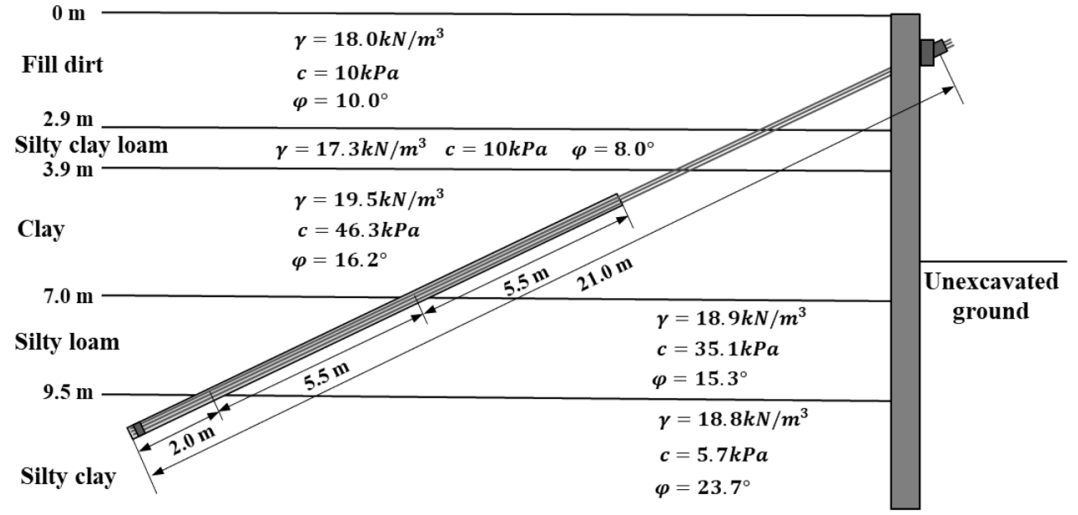

(b) Ground conditions in retaining structure

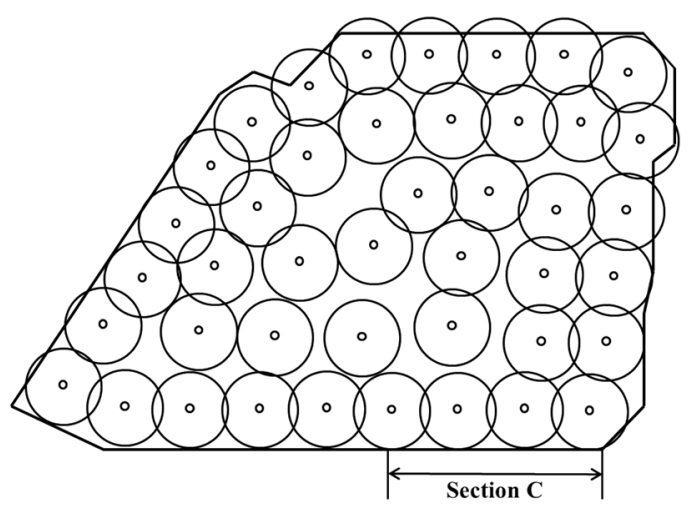

(c) Locations of drainage wells

Fig. 14 Ground condition around installed anchor 
needs to be considered in the plastic state for the calculation. Therefore, the theory of ultimate skin friction proposed by Zhenggui and Werner [39] and modified by Seo et al. [30] was applied in this paper. The equation for estimating the coefficient of pullout friction $\left(f^{*}\right)$ is:

$f^{*}=\frac{f}{1-\left[2(1+\mu) /(1-2 \mu)\left(1+2 K_{0}\right)\right] f \tan \psi}$

where $\varphi$ is $\tan \varphi, \mu$ is the Poisson's ratio, $K_{0}$ is the coefficient of lateral earth pressure at rest and $\psi$ is the dilatancy angle. The skin friction of cohesive soil $\left(\tau_{f}\right)$ can be estimated using the following equation:

$\tau_{f}=f^{*} \sigma_{m}+c$

where $\sigma_{m}$ is mean normal stress applied to the surface of an anchor and $c$ is the cohesion. The soil parameters for calculating the ultimate skin friction force were estimated by the laboratory tests, and the ultimate skin friction force calculated by Eq. (2) is shown in Table 1. The summation of ultimate skin friction forces acting on each ground was calculated as $234.5 \mathrm{kN}$, which was calculated under a drained condition (see Table 2).

In the displacement mapping results for the entire sheet pile, the displacement of most sheet piles decreased as the position of the pile element was lowered to the bottom of the pile. However, elements in rows 2 and 3 of S37 not only caused excessive displacement compared to other sheet piles (S35 and S38) as shown in Fig. 15a, but there was also greater displacement in row 3 than in the pile head (row 1). The load cell data of the anchor installed in S37 were analyzed to define the reason for the excessive displacement in rows 2 and 3 of S37. As shown in Fig. 15b, day 0 was the day when the excavation was completed, and this was the same day as that on which day 0 of laser scanning monitoring took place. When the anchor was installed, a prestress of about $95 \mathrm{kN}$ was applied. However, the load acting on the anchor increased during the excavation and the maximum load was about $231.47 \mathrm{kN}$. Then, it rapidly decreased after the excavation was completed, to about $218.37 \mathrm{kN}$. When compared with the ultimate skin friction force calculated in Table 1, the anchor was in a plastic state after the ultimate skin friction force from the excavation was mobilized. Therefore, excessive displacement occurred without an increase in the active earth pressure after the plastic state. Other sheet piles were affected by the excessive displacement of S37 caused by the plastic behavior of the anchor through the H-beam, and hence the result of displacement mapping shows a positive parabola formed from S37 and expanded horizontally.
Table 2 Evaluation of skin friction in anchor

\begin{tabular}{lllllllllll}
\hline Depth (m) & $\begin{array}{l}\text { Bonded } \\
\text { length }(\mathrm{m})\end{array}$ & $\begin{array}{l}\gamma \\
\left(\mathrm{kN} / \mathrm{m}^{3}\right)\end{array}$ & $\sigma_{m}(\mathrm{kPa})$ & $c(\mathrm{kPa})$ & $\varphi\left({ }^{\circ}\right)$ & $\Psi\left(^{\circ}\right)$ & $\mu$ & $K_{0}$ & $\tau(\mathrm{kPa})$ & $T(\mathrm{kN})$ \\
\hline $0-2.9$ & - & 18.0 & 19.58 & No grouting & & & & & \\
$2.9-3.9$ & - & 17.3 & 26.06 & & & & & & & \\
$3.9-7.0$ & 5.5 & 19.5 & 48.73 & 46.3 & 16.2 & 6 & 0.3 & 0.43 & 62.2 & 107.4 \\
$7.0-9.5$ & 5.5 & 18.9 & 66.45 & 35.1 & 15.3 & 6 & 0.3 & 0.43 & 55.3 & 95.6 \\
$9.5<$ & 2.0 & 18.8 & 73.5 & 5.7 & 23.7 & 9 & 0.33 & 0.49 & 50.1 & 31.5 \\
\hline
\end{tabular}

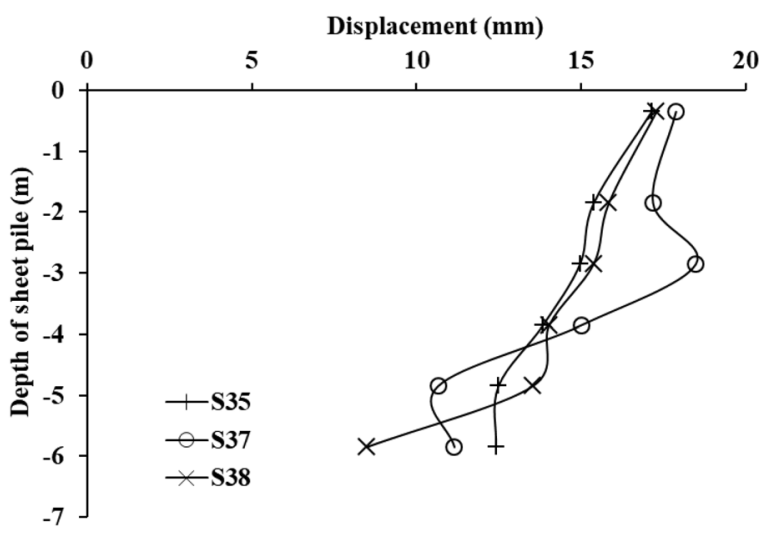

(a) $\mathrm{C} 2 \mathrm{M}$ distance results around anchor

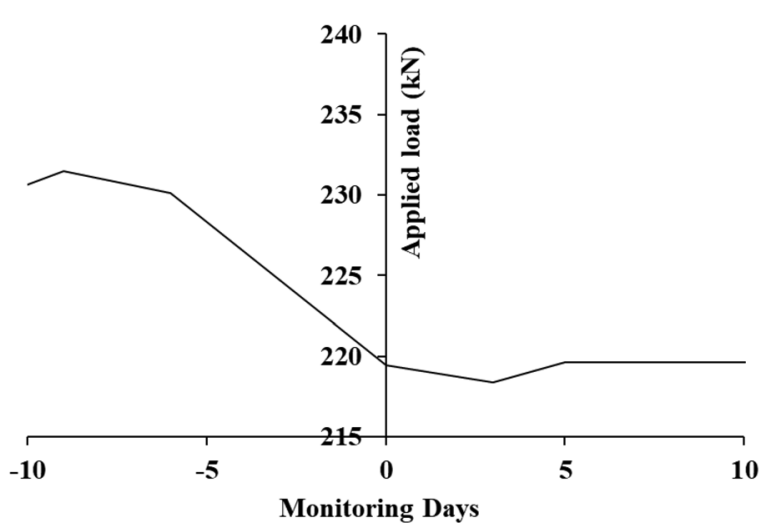

(b) Load-monitoring date curve of anchor

Fig. 15 Behavior of installed anchor 
In this paper, displacement mapping using 3-D laser scanning data was able to investigate not only the local displacement of the retaining structure but also the global displacement. Displacement mapping can locate damage to the entire retaining structure, and hence it is possible to evaluate the overall stability of a site during construction. It is also confirmed that clearer causes of structural damage can be identified when this method complements the existing monitoring system.

\section{Conclusions}

In this paper, monitoring was conducted using laser scanning after excavating the ground around the retaining structure composed of sheet piles. Displacement mapping was proposed to globally evaluate the behavior of the retaining structure induced by the excavation. The detailed conclusions are as follow:

(1) The distance between point clouds was calculated using the C2M method. Since the sheet pile consisted of a flat section and an inclined section, it was verified that displacement can be underestimated in the inclined section. Therefore, to collectively and consistently analyze all sheet piles, the point cloud for analysis was acquired by filtering the inclined section by azimuth and element angles automatically.

(2) The sheet pile was divided into 251 elements for the displacement mapping for a large-scale retaining structure which was $70 \mathrm{~m}$ in width and $6 \mathrm{~m}$ in height. The point cloud immediately after excavation was meshed, and the $\mathrm{C} 2 \mathrm{M}$ distance was calculated by comparing meshes with the point clouds obtained on the second and seventh days after excavation. The results of the displacement mapping not only showed the overall bending behavior of the retaining structure, but also that the maximum displacement occurred at S37 of the sheet pile and expanded in a positive parabolic shape in the horizontal direction. In the analysis for each row, most of the elements in the first column showed the largest displacement, and then the displacement decreased from the first to the sixth row.

(3) The field investigation was conducted based on analyzing the points at which excessive displacement and banding occurred in the displacement mapping, and cracks were found at three locations above the sheet piles. In sheet pile S37, where the maximum displacement occurred, the displacement of rows 2 and 3 was larger than for row 1, unlike the results for other piles. The total station results also show that the maximum displacement was $32.97 \mathrm{~mm}$ at $\mathrm{S} 37$, which was about $0.55 \%$ of the excavation height $(6.0 \mathrm{~m})$. The result of the load cell of the anchor acquired in the field was analyzed, and the reason of the excessive displacement was identified as being that the anchor behaved in the plastic state after it mobilized ultimate skin friction. The displacement expansion with a positive parabolic shape also indicated that the displacement induced by the anchor damage was transferred through the H-beam, which could have affected other sheet piles.

(4) Displacement mapping using 3-D laser scanning data is able to investigate not only the local behavior of a retaining structure but also the global behavior. Displacement mapping can indicate damage to an entire retaining structure, and hence it is possible to evaluate the stability of an overall site during construction. It was also confirmed that clearer causes of structural damage can be identified using this method to complement the existing monitoring system.

The main contribution of this paper is that displacement mapping was performed, after minimizing the error for a large-scale retaining structure, using laser scanning. This method is expected to contribute to monitoring the displacement of entire retaining structures.

Data availability Some or all data, models, or code generated or used during the study are available from the corresponding author by request.

Open Access This article is licensed under a Creative Commons Attribution 4.0 International License, which permits use, sharing, adaptation, distribution and reproduction in any medium or format, as long as you give appropriate credit to the original author(s) and the source, provide a link to the Creative Commons licence, and indicate if changes were made. The images or other third party material in this article are included in the article's Creative Commons licence, unless indicated otherwise in a credit line to the material. If material is not included in the article's Creative Commons licence and your intended use is not permitted by statutory regulation or exceeds the permitted use, you will need to obtain permission directly from the copyright holder. To view a copy of this licence, visit http://creativecommons.org/licenses/by/4.0/.

\section{References}

1. Allen TM, Bathurst RJ, Berg RR (2002) Global level of safety and performance of geosynthetic walls: an historical perspective. Geosynth Int 9(5-6):395-450

2. Benjamim CVS, Bueno BS, Zornberg JG (2007) Field monitoring evaluation of geotextile-reinforced soil-retaining walls. Geosynth Int 14(2):100-118

3. Bilgin Ö (2010) Numerical studies of anchored sheet pile wall behavior constructed in cut and fill conditions. Comput Geotech 37(3):399-407

4. Bosché F, Ahmed M, Turkan Y, Haas CT, Haas R (2015) The value of integrating Scan to BIM and Scan-vs-BIM techniques for construction monitoring using laser scanning and BIM: the case of cylindrical MEP components. Autom Constr 49:201-213 
5. Brilakis I, Lourakis M, Sacks R, Savarese S, Christodoulou S, Teizer J, Makhmalbaf A (2010) Toward automated generation of parametric BIMs based on hybrid video and laser scanning data. Adv Eng Inform 24:456-465

6. Caputo GV, Conti R, Viggiani GMB, Prüm C (2021) Improved method for the seismic design of anchored steel sheet pile walls. J Geotech Geoenviron Eng. https://doi.org/10.1061/(ASCE)GT. 1943-5606.0002429

7. Cherubini C (2000) Probabilistic approach to the design of anchored sheet pile walls. Comput Geotech 26(3-4):309-330

8. Chu X, Zhou Z, Deng G, Duan X, Jiang X (2019) An overall deformation monitoring method of structure based on tracking deformation contour. Appl Sci. https://doi.org/10.3390/app92 14532

9. Dias-Lalcaca P, Hack E, Visintainer F, Bernard St, Sennhauser U (2004) A laser-based instrument for measuring strain in electronic packages using coherent fibre-bundles. Microelectron Reliab 44:1693-1697

10. Hack E (2001) Application of endoscopic ESPI in NDI. In: Albertazzi A (ed) Laser metrology for precision measurement and inspection in industry, proc. SPIE 4420:107-111

11. Hack E (2005) Guest editorial: optics in Switzerland: development of lasers, optical devices and production technology. Opt Lasers Eng 43:247-249

12. Hain A, Zaghi AE (2020) Applicability of photogrammetry for inspection and monitoring of dry-stone masonry retaining walls. Transp Res Rec J Transp Res Board. https://doi.org/10.1177/ 0361198120929184

13. Hashash YMA, Oliveira Filho JN, Su YY, Liu LY (2005) 3D laser scanning for tracking supported excavation construction. In: Site Characterization and Modeling, Geo-Frontiers Congress 2005, Austin, Texas, January 24-26

14. Hashash YMA, Song H, Osouli A (2011) Three-dimensional inverse analyses of a deep excavation in Chicago clays. Int $\mathbf{J}$ Numer Anal Meth Geomech 35(9):1059-1075

15. Hassan GM (2021) Deformation measurement in the presence of discontinuities with digital image correlation. Opt Lasers Eng. https://doi.org/10.1016/j.optlaseng.2020.106394

16. Luo W, Li J, Ma X, Wei W (2020) A novel static deformation measurement and visualization method for wind turbine blades using home-made LiDAR and processing program. Opt Lasers Eng. https://doi.org/10.1016/j.optlaseng.2020.106206

17. Ma Q, Tan Y, Zhao Z, Xu Q, Wang J, Ding K (2018) Roadside support schemes numerical simulation and field monitoring of gob-side entry retaining in soft floor and hard roof. Arab J Geosci 11:563. https://doi.org/10.1007/s12517-018-3904-9

18. Mani G-F, Feniosky P-M, Silvio S (2015) Automated progress monitoring using unordered daily construction photographs and IFC-based building information models. J Comput Civil Eng. https://doi.org/10.1061/(ASCE)CP.1943-5487.0000205

19. Öser C, Sayin B (2021) Geotechnical assessment and rehabilitation of retaining structures collapsed partially due to environmental effects. Eng Fail Anal 119:104998. https://doi.org/10.1016/j. engfailanal.2020.104998

20. Qu H-L, Luo H, Hu H-G, Jia H-Y, Zhang D-Y (2018) Dynamic response of anchored sheet pile wall under ground motion: Analytical model with experimental validation. Soil Dyn Earthq Eng 115:896-906

21. Riveiro B, Dejong MJ, Conde B (2016) Automated processing of large point clouds for structural health monitoring of masonry arch bridges. Autom Constr 72:258-268

22. Scaioni M, Barazzetti L, Giussani A, Previtali M, Roncoroni F, Alba MI (2014) Photogrammetric techniques for monitoring tunnel deformation. Earth Sci Inf 7:83-95
23. Seo H (2021) 3D roughness measurement of failure surface in CFA pile samples using three-dimensional laser scanning. Appl Sci 11(6): 2713

24. Seo H (2020) Monitoring of CFA pile test using three dimensional laser scanning and distributed fiber optic sensors. Opt Lasers Eng. https://doi.org/10.1016/j.optlaseng.2020.106089

25. Seo H (2021) Long-term Monitoring of zigzag-shaped concrete panel in retaining structure using laser scanning and analysis of influencing factors. Opt Lasers Eng. https://doi.org/10.1016/j. optlaseng.2020.106498

26. Seo H, Choi H, Park J, Lee IM (2017) Crack detection in pillars using infrared thermographic imaging. Geotech Test J 40(3):371-380

27. Seo H, Lee IM, Ryu YM, Jung JH (2019) Mechanical behavior of hybrid soil nail-anchor system. KSCE J Civ Eng 23(10):4201-4211

28. Seo HJ, Choi H, Lee IM (2016) Numerical and experimental investigation of pillar reinforcement with pressurized grouting and pre-stress. Tunn Undergr Space Technol 54:135-144

29. Seo HJ, Choi H, Lee KH, Bae GJ, Lee IM (2014) Pillar-reinforcement technology beneath existing structures: Small-scale model tests. KSCE J Civ Eng 18(3):819-826

30. Seo HJ, Jeong KH, Choi H, Lee IM (2012) Pullout resistance increase of soil nailing induced by pressurized grouting. J Geotech Geoenviron Eng 138(5):604-613

31. Seo HJ, Lee IM, Lee SW (2014) Optimization of soil nailing design considering three failure modes. KSCE J Civ Eng 18(2):488-496

32. Seo HJ, Zhao Y, Wang J (2019) Monitoring of retaining structures on an open excavation site with 3D laser scanning. In: International conference on smart infrastructure and construction 2019 (ICSIC), Cambridge https://doi.org/10.1680/icsic.64669.665

33. Soga K, Kwan V, Pelecanos L, Rui Y, Schwamb T, Seo H, Wilcock M (2015) The role of distributed sensing in understanding the engineering performance of geotechnical structures. In: XVI European conference on soil mechanics and geotechnical engineering, Edinburgh

34. Su YY, Hashash YMA, Liu LY (2006) Integration of construction as built data via laser scanning with geotechnical monitoring of urban excavation. J Constr Eng Manag 132(12):1234-1241

35. Su YY, Hashash YMA, Quiñones-Rozo CA, Groholski DR (2009) Tracking of excavation activities by laser scanning and image reasoning-based techniques. Geotechnical News 27(1):35-37

36. Su YY, Song H, Liu LY, Hashash YMA (2005) Field tests of 3D laser scanning in urban excavation. In: Oliveira Filho (ed) Computing in civil engineering. 2005 International conference on computing in civil engineering, Cancun, July 12-15

37. Tan Y, Paikowsky SG (2008) Performance of sheet pile wall in peat. J Geotech Geoenviron Eng 134(4):445-458

38. Yang H, Omidalizarandi M, Xu X, Neumann I (2017) Terrestrial laser scanning technology for deformation monitoring and surface modeling of arch structures. Compos Struct 169:173-179

39. Zhenggui W, Werner R (2002) A study of soil-reinforcement interface friction. J Geotech Geoenviron Eng 128(1):92-94

Publisher's Note Springer Nature remains neutral with regard to jurisdictional claims in published maps and institutional affiliations. 